\title{
An Intersemiotic Analysis of Pictures in Translated and
}

\section{Non-Translated Children's Literature}

\author{
Abbas Saeedipour ${ }^{1} \&$ Nasrin Qorbani Sharif ${ }^{2 *}$ \\ ${ }^{1}$ English Language and Literature Department, Faculty Member of Payame Noor University, Qom, \\ Iran \\ ${ }^{2}$ M.A. English Language Teaching, Payame Noor University, Qom, Iran \\ * Nasrin Qorbani Sharif, E-mail: afsaneyeshirin@gmail.com
}

Received: October 2, 2016

Accepted: October 8, 2016

Online Published: October 14, 2016

doi:10.22158/selt.v4n4p461

URL: http://dx.doi.org/10.22158/selt.v4n4p461

\begin{abstract}
Illustrations in books play a significant role in the development of the story by re-narrating the story which is also presented in linguistic forms (words). This process is a type of translation (intersemiotic) as proposed by Jacobson (2000). Also words being accompanied by illustrations help children to better involve in and understand the story. Therefore it is necessary to pay close attention to the illustrations and the relationships they hold with the linguistic texts of the story. There seems to be differences between English and Persian children's story books in terms of illustrations. The study and investigation of the importance as well as strengths/weaknesses of illustrations in original Persian stories for children can help writer develop better strategies to organize their stories in both linguistic forms and illustrations. In the present study a number of translated and original Persian children story books were collected. All the books have illustrations which accompany the texts of the books. Then all the texts were study carefully, analyzed and compared with their accompanying pictures (or illustrations). Each picture was analyzed based on its relationship with the corresponding text. The results of the study revealed that there are significant differences in illustrations in translated and non-translated children story books.
\end{abstract}

\section{Keywords}

intersemiotic translation, Children's Literature, translation and non-translation, illustration

\section{Introduction}

Children's Literature $(\mathrm{ChL})$ is an almost new area within Translation Studies. Scholars became interested in $\mathrm{ChL}$ when the demand for reading books of other parts of the world, especially of neighbors, began. Oittinen (2000) defines $\mathrm{ChL}$ as "the literature read silently by children and aloud to them" (p. 6). 
Jacobson (1959) introduces three different types of translation, i.e., intralingual, inter-lingual and intersemiotic. He explains that translation can take place between two systems of signs (intersemiotic translation). He also states that intersemiotic translation, the third type of translation, involves the conversion of a particular system of signs in to a different configuration.

Intersemiotic translation was defined by Jakobson as "transmutation of signs" - "an interpretation of verbal signs by means of signs of non-verbal sign systems" (in Venuti, 2000, p. 138).

Children's literature is overlooked in terms of technical issues including content, language and illustration. The idea here is that the interaction between picture and words in picture books seems to be underestimated in most of books written for children.

Many people accept that literature, either original or translated, is the best way to stimulate the world and surroundings of children. However, $\mathrm{ChL}$ has a marginal position in the literary system and has little influence.

If we accept this fact, then we should appreciate the importance of this field of study and try to give it the attention it deserves. The present study focuses on of the aspects of children's story books, which seems to be deemed unworthy, i.e., illustrations. Illustrations in books play a significant role in the development of the story by re-narrating the story which is also presented in linguistic forms (words). This process is a type of translation (intersemiotic) as proposed by Jacobson (2000).

There seems to be differences between English and Persian children's story books in terms of illustrations.

The study and investigation of the importance as well as strengths/weaknesses of illustrations in original Persian stories for children can help writer develop better strategies to organize their stories in both linguistic forms and illustrations.

Also words being accompanied by illustrations help children to better involve in and understand the story. Therefore, it is necessary to pay close attention to the illustrations and the relationships they hold with the linguistic texts of the story.

The present study seeks to investigate an overlooked issue in children's story books, i.e., the importance of illustrations in children story books, and the way illustrations play a different role in translation vs. non-translation Persian stories.

\section{Research Questions}

Q1. What is the importance of illustrations in children story books as an intersemiotic translation?

Q2. How are illustrations different in translated and non-translated children story books?

\section{Children's Literature}

\subsection{Definition}

Children's Literature doesn't have a clear definition; Oittinen (2000, p. 4) defines generally children's literature as: "literature read silently by children and aloud to children". 
McDowell (1973) defines children's books by referring to certain features:

They are generally shorter; they tend to favor an active rather than a passive treatment, with dialogue and incident rather than description and introspection; child protagonists are the rule; conventions are much used; they tend to be optimistic rather than depressive; language is child-oriented; plots are of a distinctive order, probability is often discarded; and one could go on endlessly talking of magic and fantasy and simplicity and adventure (as cited in Hunt, 1991, p. 54).

\subsection{Status}

Children's books, and hence their writers, are often less apt to be considered of high importance.

Clark (1993) holds that the attitude shown towards the authors of children's books is "condescending" (p. 1). They are, somehow, seen as if they were the same age as their audience or still at a learning stage. Starting off a career by writing children's books is regarded as ideal; it will be easy and, in the case of a failure, not much harm will be done because "it is only for children".

Children's literature is believed to be less demanding than literature for adults and, therefore, of less value and interest.

\subsection{Functions of Children's Literature}

Children's literature is usually seen as a mode of moral instruction. Children should be taught, as far as they are permitted to concern themselves with the characters of those around them, to seek faithfully for good things. One of the important functions of Children's literature is to guide children in this path. Literature should teach morality at the same time that it entertains children.

\subsection{Illustration and Translation}

\subsubsection{Why are Illustrations Translations}

What Tymoczko (1999, pp. 41-61) describes as the metonymic nature of translation can also be applied to illustration. According to Tymoczko (1999, p. 54), translations are always carried out in a metonymic way. Because texts are loaded with textual, linguistic, historical, and cultural values that cannot be wholly reproduced in the translated text, translators have to make choices:

Pictures can translate words in the same way words translate words. Pereira (2008) suggests the following:

By literally reproducing the textual elements in the picture: Literal intersemiotic translation is perhaps the most obvious way through which textual elements can be translated into visual elements.

By emphasizing specific narrative elements: By this strategy, one or more elements of textual narrative (character, point of view, action, theme, etc.) direct the visual narration in the drawings.

By adapting the pictures to a specific ideology or artistic trend: By this strategy the illustrations can be directed to a specific audience, a specific ideology or a specific artistic trend, according to the time when the pictures are produced and the illustrator's values and ideology.

\subsection{The Importance of Illustration for Children}

For preschool children, written words are an inaccessible territory. Through the illustrations, preschool children can read and understand the story. As children are able to "read" the book by themselves, they 
accomplish a sense of control, success and independence. The more dominant the role of the illustrations in the book, the better children can decode the book and understand it on their own.

In order to examine the children's experience, we should first look at the book's illustrations alone. Then we should read the text independently and finally read the two channels together, examining the dialog between them.

The illustrations add a significant narrative dimension to the book. The visual channel, the pictures a child can "read" independently, is dominant. The child, who "reads" the illustrations, fully understands the book, while the adult, who reads the text aloud, articulates his own limited, literal perception.

The dialog between illustration and text is essential to every picture-book.

\section{Methodology}

\subsection{Source Materials}

The corpus of the present study consists of 19 children story books. A number of the books ( 9 of them) were English story book which have been translated into Persian. The rest of the books (11 of them) were original Persian story books. Therefore, the corpus is parallel. In other words, the corpus consists of 19 translated and non-translated Persian story books. All the story books have illustrations.

The list of original (non-translated) story books is as follows:

Once spring arrived

Taqi, Sh. (2013). Once spring arrived. Institute for the Intellectual Development of Children and Young Adults: Tehran.

Are you my mother?

Shams, M. (2008). Are you my mother? Institute for the Intellectual Development of Children and Young Adults: Tehran.

Hey! Will you be my friend?

Kalhor, M. (2005). Hey! Will you be my friend? Institute for the Intellectual Development of Children and Young Adults: Tehran.

Little lamb's garden

Haqparast, N. (2013). Little lamb's garden. Institute for the Intellectual Development of Children and Young Adults: Tehran.

The legend of bald birdman

Barjasteh, L. (2013). The legend of bald birdman. Institute for the Intellectual Development of Children and Young Adults: Tehran.

Once upon time!

Taqdis, S. (2013). Once upon a time. Institute for the Intellectual Development of Children and Young Adults: Tehran.

Cloud goats

Shabannejad, A. (2008). Cloud goats. Institute for the Intellectual Development of Children and Young 
Adults: Tehran.

The account of a lion who was $\mathrm{s}$

Haqparast, N. (2008). The account of a lion who was sad. Institute for the Intellectual Development of Children and Young Adults: Tehran.

Stair game

Katbi, S. (2004). Stair game. Institute for the Intellectual Development of Children and Young Adults: Tehran.

The account of Ahmad and the little baby.

Tavakoli, N. (2013). The account of Ahmad and the little baby. Institute for the Intellectual Development of Children and Young Adults: Tehran.

The Account of Uncle Nowruz and Aunt Spring

Qasemnia, Sh. (2014). The Account of Uncle Nowruz and Aunt Spring. Institute for the Intellectual Development of Children and Young Adults: Tehran.

The list of translated story books is as follows:

Don't let the pigeon drive the bus

Mo, W. (2007). Don't let the pigeon drive the bus. Institute for the Intellectual Development of Children and Young Adults: Tehran.

Little hungry boy

Delye, P. (2013). Little hungry boy. Institute for the Intellectual Development of Children and Young Adults: Tehran.

Yellow and pink

Steig, W. (2013). Yellow and pink. Institute for the Intellectual Development of Children and Young Adults: Tehran.

Where I am?...

Butterfield, M. (2001). Where I am?... Institute for the Intellectual Development of Children and Young Adults: Tehran.

The Gruffalo

Donaldson, J. (2015). The Gruffalo. Institute for the Intellectual Development of Children and Young Adults: Tehran.

Farmer duck

Waddell, M. (2014). Farmer duck. Institute for the Intellectual Development of Children and Young Adults: Tehran.

How to cure a broken wing?

Graham, B. (2014). How to cure a broken wing? Institute for the Intellectual Development of Children and Young Adults: Tehran.

Here is mine

Rui Llier, J. (2014). Here is mine. Institute for the Intellectual Development of Children and Young Published by SCHOLINK INC. 
Adults: Tehran.

Marvin gets mad

Theobald, J. (2015). Marvin gets mad. Institute for the Intellectual Development of Children and Young Adults: Tehran.

\subsection{Type of Research}

The present study makes use of a number of children story books, some of which are originally written in Persian, while the rest have been translated into Persian. Therefore, this is a corpus-based study. Also, since the texts are not the translations of each other therefore the corpus of the present study is a comparable one.

The study is also descriptive in nature since it tries to explain and compare/contrast the relationship between linguistic texts and illustrations in translated and non-translated Persian children's story books.

\subsection{Data Collection}

In order to collect the data for the present study a number of translated and original Persian children story books were collected. All the books have illustrations which accompany the texts of the books. Then all the texts were study carefully, analyzed and compared with their accompanying pictures (or illustrations). Each picture was analyzed based on its relationship with the corresponding text.

\subsection{Data Analysis}

Looking from an intersemiotic point of view, it is believed that illustrations have specific relationships with their corresponding texts. These relations can be described as metonymic. In children story books, in particular, pictures accompany texts in order to make them more interesting and also to make it easier for the children to follow the story. Therefore, in the present study all the pictures, after being placed next to their corresponding texts, were explained in terms of their clarity. In other words, it was attempted to make show how well illustrations in translated and non-translated children story books represent the content of the stories.

\section{Findings and Results}

\subsection{Non-Translation (Original) Stories}

The first part of the analysis is devoted to stories which are originally written in Persian. Therefore, there is no translation. The aim of the present section is to investigate the way texts are translated by their accompanying pictures; in other words, how illustrations come to complement texts.

Two criteria were taken into consideration for the selection of the books. First, all the stories contained texts as well as illustrations. This was needed because the focus of the present study is on the intersemiotic translation between texts and illustrations in children's stories, and how they may be different in translated and non-translated stories. Also, all the authors and illustrators were Iranian. This was of great importance since we wanted to check the difference between illustrations by Iranian (original) illustrators and those of foreign illustrators.

All the 11 stories were studied and analyzed. Two pages of each story are taken here for analysis and 
discussion.

These two pictures are taken from The legend of bald birdman.
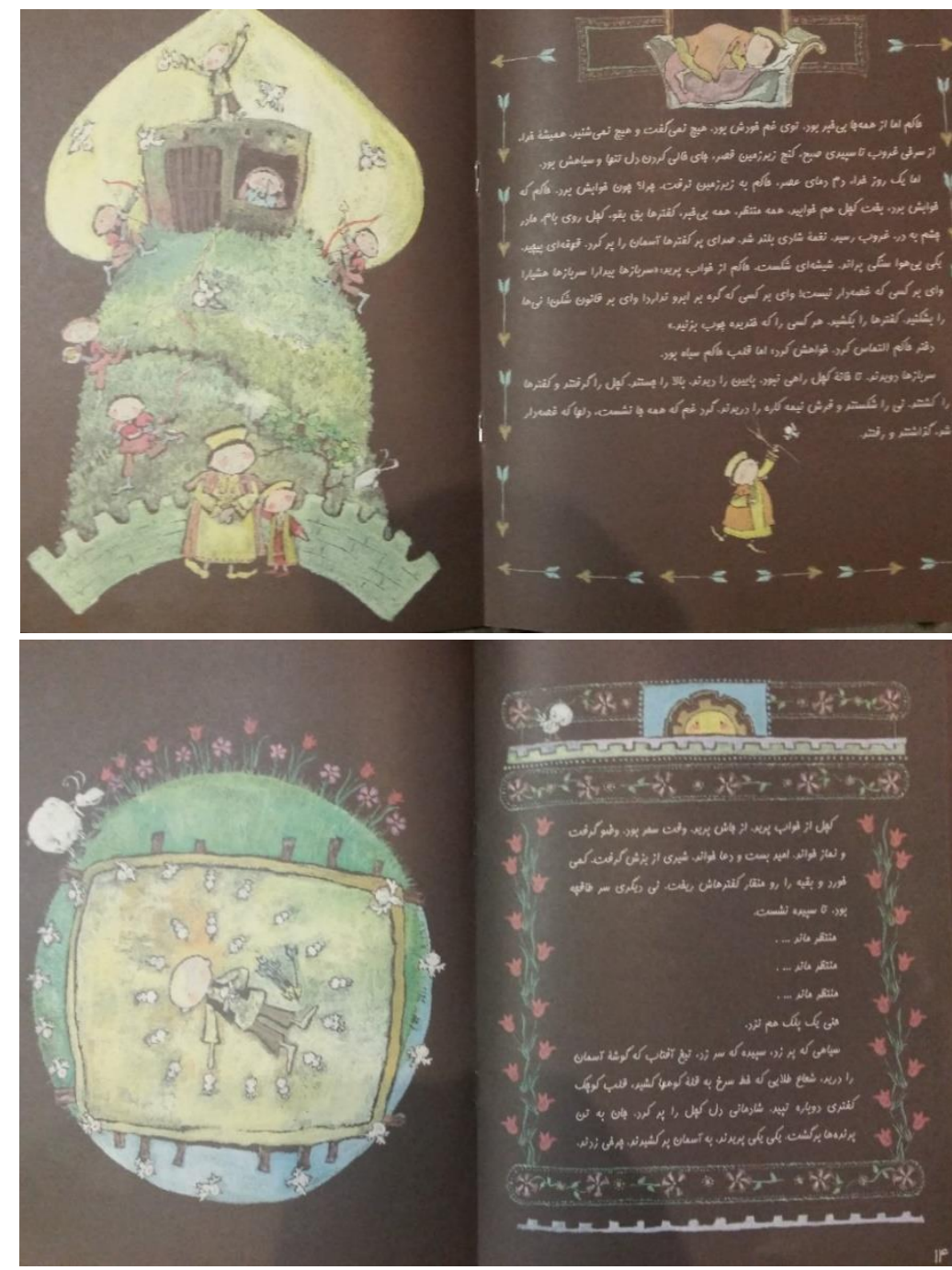

Figure 1. The Legend of Bald Birdman

The text in the first picture is narrating part of the story. This includes the King's sadness, his sleep, the place he sleeps in, and other actions including happiness, breaking the window as well as the King's daughter who is begging his father. However, as we can see in the illustration only some specific events are reproduced. This is also worsened by the low-quality unreal faces of the people, which do not convey appropriately the emotions of the characters, which are stated in the verbal text.

Regarding the second illustration in the second picture, most of the themes stated by the verbal text are not mentioned in the illustration. Therefore, the picture is very static and does not help the narration of the story. The awaking of the character, his prayer, several action he does, etc. None of them are reproduced nor complemented by the illustration.

Another point which is true for both illustrations is the unrealistic style of them. In fact, they would be 
more tangible for children if they had been more real.

\subsection{Translated Stories}

The second part of the analysis is the investigation of translated stories into Persian. These stories include stories which are originally written and illustrated in English but translated into Persian; in other words, the illustrations are not from Iranian illustrators. This could help the researcher to compare the illustrations done by Iranian and English illustrators, and the way they accompany and complement texts.

The next two illustrations are taken from Farmer Duck.
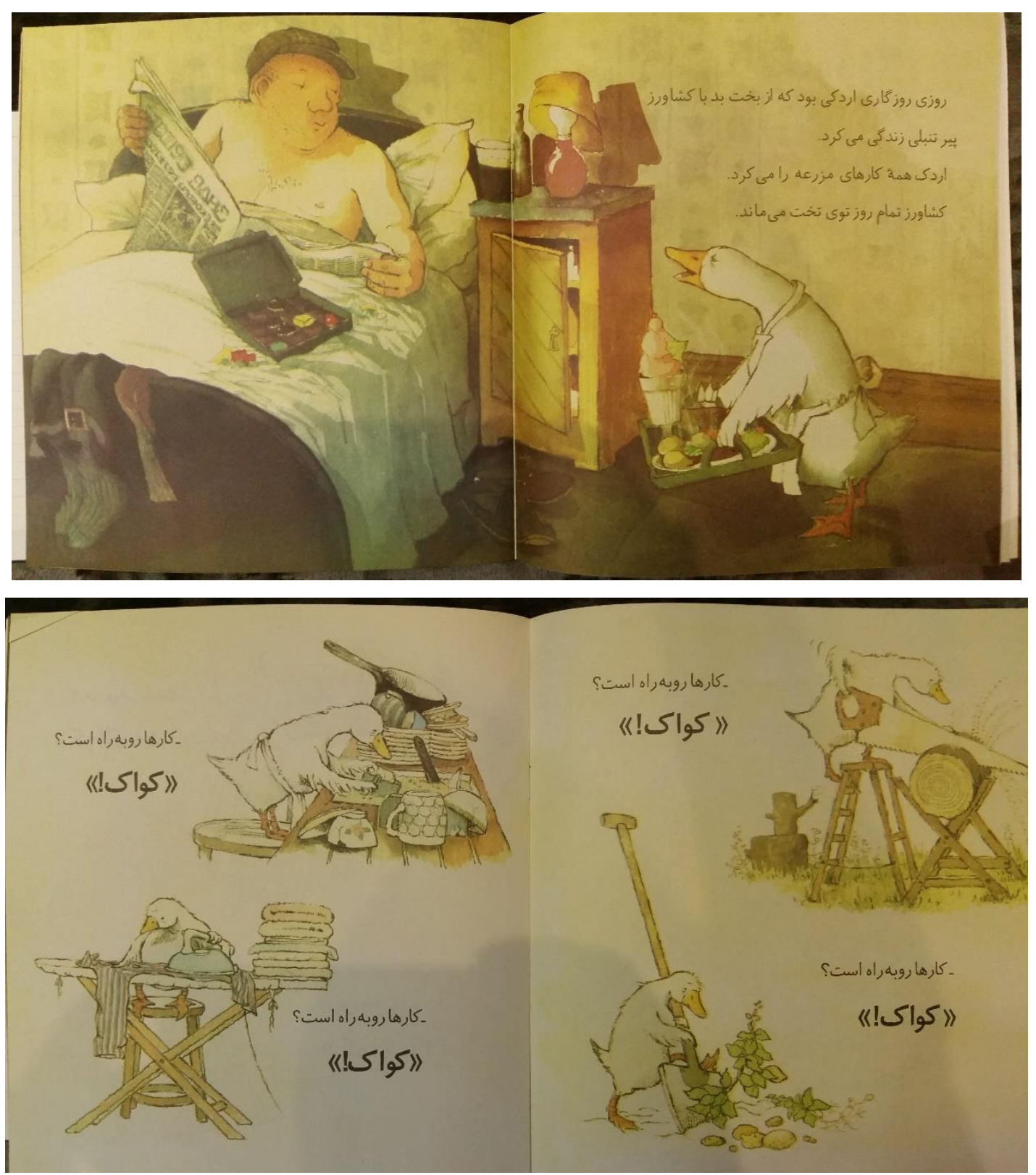

Figure 2. Farmer Duck 
The story is about a hardworking duck and its lazy owner. Again here the illustrations are of high quality and they are easy to recognize. What is described by the verbal text can be seen in the illustrations, and the details observed in the illustrations and the ways characters are presented closely correspond to the adjectives used in the verbal text.

The second picture is a very special case. Here the illustrations perfectly complement the verbal text in a way that one can follow the events of the story by looking at the pictures. Complementarity seems to be of great importance in children's stories; this feature helps children recognize different events, actions and phenomena and relate them to the reality.

\section{Discussion}

In the previous section two types of short stories were analyzed: the first type included English short stories with English illustrators, which are translated into Persian but the English illustrations are kept. The second type included original Persian short stories with Iranian illustrators. The texts were studied and compared with their corresponding illustrations. The goal was to see whether there is any difference between the role of illustrations in English and Persian children short stories. Also, we wanted to see what different ways in which illustrations accompany the verbal texts.

The analyses revealed some significant points:

Verbal and non-verbal texts in original Persian (non-translated) short stories:

Facial expressions are vague, neutral or different from what is expressed verbally in the text. The analysis of 11 original Persian children short stories with more than 100 illustrations was really revealing in this regard. The analysis indicated that for most of the illustrations in original Persian stories there was not an appropriate match between what was verbally expressed by the words about the emotions and feelings of the characters and how they were depicted by the illustrations. There were cases were the facial expressions were vague and therefore impossible to recognize what they were supposed to convey. Some other cases included neutral facial expressions and not conveying any emotion, although in the text some kind of emotion was mentioned. Also there were example of cases where the text mentions the happiness of one character; however, what one can see in the illustration is the surprise of the character.

Some of the illustrations are repeated without any change. This problem was quite disappointing, since it indicates a lack of awareness of the importance of illustrations in children's story books. There were cases where, for whatever reason, the same picture, say of a sheep, was copied in three or four pages. This seems quite unprofessional; using the same picture for different contexts conveys a lack of skill on the side of the illustrator.

The illustrations are not realistic. Talking of cartoons is one thing and illustrations which (sometimes) have no resemblance to reality is quite something different. It is obvious that illustrations for children's story books have specific features: they are "child-friendly", and they exaggerate some parts of the reality, etc. However, they also have obvious resemblance to the reality so that children can recognize 
them as such. Unfortunately, this was not the case regarding some of the original Persian stories; there were cases where it was too difficult, if not impossible, to recognize what the illustration aims to represent.

The illustrations depict only one or two among several characters and the focus is on one character or one static event and not on the continuity of events. This was a common shortcoming for most of the stories in this section. For example, there was a dialogue between two characters; however, the only thing illustrated was two faces without any clue to what was going on between them.

The illustrations have some kind of "displacement"; something is expressed in one page verbally but the related illustration is given in the next page. This is quite confusing for a child who is listening to his/her mother reading the story and at the same time looking at the pictures, since what he expects to find in one page he will see in the next page. It is quite similar to changing the order of material in a text during the process of translation, which lead to the loss of cohesion and consequently coherence of the text.

A considerable number of illustrations seem to serve only as fun; in other words, just to fill the page and make it seem more colorful and happy. These included illustrations which did not serve any purpose. The illustrations are meant to create or re-create part of what is intended to be conveyed to the audience.

Most of the illustrations are of surprisingly low quality. This is also something which may seem marginal, but is of high importance. Education requires quality and the quality of the material is a major part of that. The low quality of the illustrations in some cases hiders communication.

Omission could be seen just in the same as proper translation. Intentionally or not it happens that during the process of proper translation, i.e., translating a text from one language to another, some parts of the text is simply omitted. The same process happens in intersemiotic translation where what is expressed verbally is not re-produced by visual elements (illustrations). However; if these omissions are excessive then the cohesion between the verbal text and illustrations is lost, which in turn leads to lack communication on the side of the child audience.

In short, regarding the importance of illustration in translation (of children's story books in particular) one can claim that similar to translation of poetry, illustration is only possible through the re-creation of the textual elements and values in the pictures. They are different in terms of the sign system, but constitute another construct of the (same) text in the universe of the illustrated book.

Verbal and non-verbal texts in translated short stories:

Illustrations may narrate the story. As it was mentioned in the analysis there was a very strong and close interaction between verbal texts and illustrations. In fact, the illustrations were employed very skillfully to complement the verbal texts. Therefore, there were many examples where there was one single sentence or even no words on a page and the story could be followed by the illustrations. In other words, what was expected to be narrated for the audience was translated into illustrations. There could be several reasons for this: a. illustrations are sometimes more powerful in conveying meanings, $b$. this 
could make the story less boring and much of a fun.

The illustrations are dynamic rather static (as it was in original Persian non-translated short stories). The pictures were not the depiction of one character or event; rather, in the same was that the words and sentences tell the whole story, the illustrations could, for the most part, be followed and the story could be understood.

Illustrations are extremely educational. Therefore, they are used with pedagogical purposes. Illustrations are seen as a process of intersemiotic translation; however, can serve different goals. Sometimes they are employed as a translation strategy to facilitate understanding. In addition to this, illustrations can serve educational purposes in children's story books. This includes introducing them different objects in the world around them, different processes (how a loaf of bread is baked, for example), different personalities and traits etc.

\section{Conclusion}

\subsection{Restatement of Research Questions}

Q1. What is the importance of illustrations in children story books as an intersemiotic translation?

First and foremost, the present study sought to investigate the significance (if any) of illustrations as type of translation in children's story books. The researcher started with a common assumption and checked the validity of that; this was done through the analysis of a number of translated and non-translated Persian children's story book.

It has also been a common assumption that, because illustrations are often derived from the text, they are a secondary or inferior art (Behrendt, 1997, p. 24). However, this should not lead to the underestimate of the significance of illustrations. The problem arises once we (and the illustrator) sees illustrations (and especially for children's story books) merely as something to make the pages more colorful. Illustrations do serve various purposes the least significant among which is the happy face of the pages.

Looking at illustrations as a (intersemiotic) translation — what the present study was after-gives illustrations a significant position. With such an approach illustrations are part of the meaning-communicating system. They are employed purposefully to produce or re-produce part of the meaning as intended by the author.

Illustrations are also facilitators of the communication - the communication between the author and the child audience. Therefore, whenever there are concepts, objects or events which may be unknown to the novice child audience the illustrations come to help and visualize them, which is easier to understand for the children.

Furthermore, illustrations are educational. Because of their age, young children are more visual learners. They are less familiar with the abstract world of written verbal language; therefore, many of the things which are to be taught to them can be presented in the form illustrations.

Illustrations, therefore, not only help transmit but also perpetuate educational elements. They help 
children to hear things as well as see them.

Q2. How are illustrations different in translated and non-translated children story books?

The findings of the study were quite revealing. There were significant differences in illustrations in translated and non-translated children story books. The differences were evident in the quality, the style as well as the purpose of the illustrations

According to Tymoczko (1999, p. 54), translations are always carried out in a metonymic way. This means that translations do not match all the aspects of the source text, but rather some parts of the source text are taken to the target text and some other parts are left "un-transferred".

As one of the main aims of the present study, illustrations can especially be seen as translations because as a process, the methodologies employed by illustrators are in the majority of cases the same as those adopted by translators to translate a text; and as products, illustrations play a very significant part in the reception of the literary work.

The text can be regarded as the primary source because it is usually the first work to be created, the pictures being derived from it.

Similar to translation of poetry, illustration is only possible through the re-creation of the textual elements and values in the pictures. They are different in terms of the sign system, but constitute another construct of the (same) text in the universe of the illustrated book.

\section{References}

Clark, M. (1993). Writing for Children. London: A\&C Black (Publisher) Ltd.

Hunt, P. (1991). Criticism, Theory and Children's Literature. Cambridge: Blackwell Inc.

JAKOBSON, R. (1959). On Linguistic Aspects of Translation. In L. VENUTI (Ed.), The Translation Studies Reader (pp. 137-147). London and New York, Routledge. http://dx.doi.org/10.4159/harvard.9780674731615.c18

OITTINEN, R. (2000). Translating for Children. New York and London, Garland Publishing Co.

Pereira, N. M. (2008). Book Illustration as (Intersemiotic) Translation: Pictures Translating Words. Meta: journal des traducteurs [Meta: Translators' Journal], 53(1), 104-119. http://dx.doi.org/10.7202/017977ar

TYMOCZKO, M. (1999). Translation in a Postcolonial Context. Manchester, St. Jerome.

Venuti, L. (2000). The translation study readers. London: Routledge. http://dx.doi.org/10.4324/9780203446621 